Universidade de Brasília

Instituto de Ciências Humanas

Departamento de Serviço Social

“O VER-SUS/Brasil e a formação em saúde dos estudantes de Serviço Social”

Thallyta de Carvalho Tomimatsu- mat.: 02/28800

Brasília, DF 
Universidade de Brasília - UNB

Instituto de Ciências Humanas - IH

Departamento de Serviço Social - SER

\section{“O VER-SUS/Brasil e a formação em saúde dos estudantes de Serviço Social”}

Trabalho de Conclusão de
Curso apresentado como
requisito para a aquisição do
grau de Assistente Social no
curso de Serviço Social da
Universidade de Brasília.

Thallyta de Carvalho Tomimatsu 02/28800

Professor: Mário Ângelo Silva 
“Ou os estudantes se identificam com o destino do seu povo, com ele sofrendo a mesma luta, ou se dissociam do seu povo, e nesse caso, serão aliados daqueles que exploram o povo.”

Florestan Fernandes 


\section{Agradecimentos}

Agradeço a todas as pessoas que me acompanharam nesse caminhar e o tornaram bem mais acolhedor. Especialmente aos companheiros do Movimento Estudantil pelos importantes momentos de luta e aprendizado que dividimos. Aos professores do Departamento de Serviço Social da UnB que nos provam a cada dia que uma universidade publica, gratuita e de qualidade é possível, apesar da constante ofensiva neo-liberal, em especial ao professor Mário Ângelo que soube contribuir enormemente para a construção desse trabalho. As amigas por se fazerem sempre presentes. Ao Leonardo pelo amor e companheirismo. Aos meus irmãos Pollyanna e Andrey pelos aprendizados. A minha mãe

pelo amor que nos une. E ao meu pai por tornar seus os meus sonhos e tornar possível cada um deles. 


\section{Glossário de Siglas}

CNS - Conselho Nacional de Saúde

DENEM - Diretoria Nacional dos Estudantes de Medicina

ENESSO - Executiva Nacional dos Estudantes de Serviço Social

ENIV-SUS - Estágio Nacional Interdisciplinar de Vivência no Sistema Único de Saúde

ESP/RS - Escola de Saúde Pública do Rio Grande do Sul

FEAB - Federação dos Estudantes de Agronomia do Brasil

IES - Instituição de Ensino Superior

MS - Ministério da Saúde

NETESC - Núcleo de Trabalhos em Saúde Coletiva

OMS - Organização Nacional de Saúde

SS - Serviço Social

SUS - Sistema Único de Saúde

VER-SUS/Brasil - Vivências e Estágios na Realidade de Sistema Único de Saúde do Brasil VER-SUS/RS - Vivências e Estágios na Realidade de Sistema Único de Saúde do Rio Grande do Sul 


\section{Sumário}

Páginas

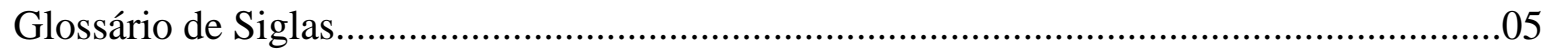

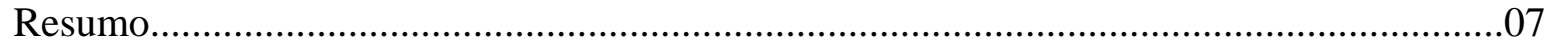

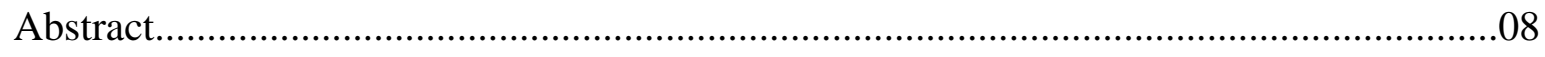

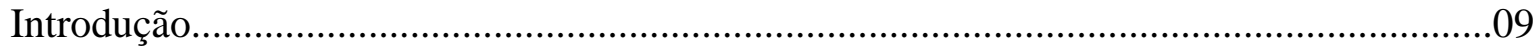

01. Abordagem Teórico-Metodológica......................................................................18

02. Apresentação e Análise do Objeto de Estudo: O VER-SUS/Brasil na perspectiva dos

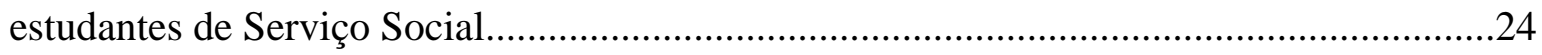

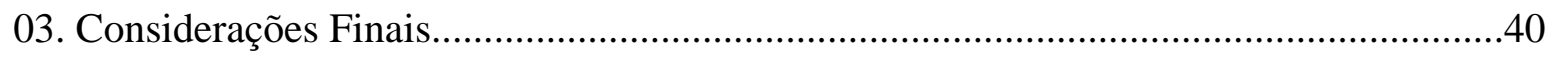

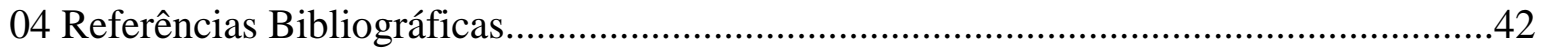

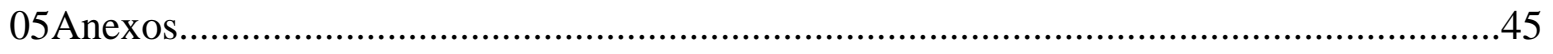




\section{$\underline{\text { Resumo }}$}

Essa monografia buscou tratar da formação profissional dos estudantes de Serviço Social na área da saúde. Tendo como sujeitos de pesquisa os estudantes de Serviço Social que participaram do projeto Vivências e Estágios na Realidade do Sistema Único de Saúde - VER-SUS/Brasil no ano de 2004. Partiu da constatação que esses estudantes, assim como as demais profissões da saúde, tem pouco contato com a realidade e os desafios do SUS. Entretanto, essa pesquisa propôs-se a analisar estratégia VER-SUS/Brasil na formação de estudantes universitários de Serviço Social através da identificação de suas expectativas, bem como suas impressões posteriores sobre o referido estágio de vivência, contribuindo, assim, para uma maior compreensão da formação dos assistentes sociais no que concerne à política de saúde e suscitando reflexões sobre a formação profissional como um todo. Partindo da hipótese de que os estágios, tanto no que se refere ao seu cenário de realização quanto as vivências que proporcionam, são um importante complemento para a formação em saúde de assistentes sociais

Palavras-chave: Sistema Único de Saúde, formação profissional em Serviço Social, ensino-aprendizagem, VER-SUS/Brasil 


\section{$\underline{\text { Abstract }}$}

This paper has aimed to approach the professional formation of the Social Service students in the public health system. The subjects of this research are the Social Service students who participated in the project "Experiences and Internships in the Unified Health System Reality - VER-SUS/Brazil” in 2004. It has started from the verification that those students as most of the health professionals have little contact with the reality and the challenges presented by the Unified Health System. However, this research has proposed to analyze the VER-SUS/Brazil strategies for the formation of college students that are graduating in Social Service through the identification of their expectations as well as their post impressions on the referred experience internships, contributing thus to a greater comprehension of the formation of the social workers concerning health policies and reflections about the professional formation as a whole. The hypothesis is that the internships are an important complement to the formation of the social workers in Health, as much for the scenario where they take place as for the experiences they provide.

Keywords: Brasilian System Health (SUS), Professional formation in Social Work, teaching-learning, VER-SUS/Brasil 


\section{INTRODUCÃO}

A expressão “questão social” é usada para designar as grandes transformações sociais, políticas e econômicas ocorridas na Europa em decorrência da revolução industrial. Configura-se, segundo Castel (apud STEIN, 2000, p. 134), a partir da "tomada de consciência” das condições de existência das populações que são, ao mesmo tempo, os agentes e as vítimas da revolução industrial. A questão social é, assim, o conjunto das adversidades produzidas pela sociedade capitalista, e sua configuração é decorrente da situação da luta de classes no momento histórico em que foi produzida.

O Serviço social é uma profissão que atua diretamente na questão social. A questão social é notoriamente reconhecida como foco central da atuação profissional do Assistente Social por diversos autores e estudiosos da categoria (IAMAMOTO, 2000; PEREIRA, 2000; SERRA,2000). Para Netto (2001), por exemplo, é o que confere sentido à profissão. Assim, o Serviço Social se institui como profissão enquanto mecanismo institucional utilizado pelo Estado para intermediar as expressões da questão social e o Estado (SERRA, 2000).

Essa relação do Estado com a questão social acontecerá principalmente com a formulação das políticas públicas, o que, também, se configura como campo de atuação profissional importante e mercado de trabalho das assistentes sociais (IAMAMOTO, 2000). É assim que o Serviço Social, na área da saúde, vem sendo estudado: a partir da mediatização da relação Estado - sociedade por meio de políticas públicas de saúde, da ação dos profissionais e pelos movimentos sociais.

Como podemos observar ao longo do processo de construção da política de saúde no Brasil ela foi permeada por interesses diversos, de forma que a participação social pode 
ser considerada um fator fundamental dentro do Estado, uma vez que essa participação possibilita a divisão do poder, além de associar instrumentos de democracia direta e representativa, concomitantemente, enfatizando nos espaços públicos a importância da representação e negociação, visando politizar a participação considerando a gestão como um espaço de interesses que devem ser reconhecidos e negociados (IAMAMOTO, 2000). Ou seja, a participação popular tem um papel imprescindível para fazer proporcionar as mudanças necessárias, legitimar a política do Estado (VALLA,1998) e qualificar essas políticas, como se nota no caso de governos populares.

O Estado, na visão de Gramsci, é também palco para a luta de classes que produz e dá a configuração histórica da questão social. Assim, as políticas públicas construídas pelo Estado para fazer frente à questão social estão sujeitas às configurações da luta de classes de um período histórico específico. Nesse sentido, a política de saúde, formalmente reformulada na década de 90, contou com a influência do movimento da Reforma Sanitária que colocava-se em oposição à mercantilização da saúde como parte da tendência mundial da globalização neoliberal. A saúde, então, foi inscrita na Constituição de 1988 como “direito de todos e dever do Estado”, reafirmando o ideário da Reforma Sanitária e elevada ao status de direito social, formando com a previdência e a assistência o tripé da Seguridade Social. Entretanto, na contra-mão desse sistema aprofundou-se a da política neoliberal adotada nos últimos anos, acarretando o aumento da demanda do sistema de proteção social, a submissão da política social aos interesses econômicos e a conseqüente dificuldade de implementação e consolidação deste sistema de proteção. Como resultado, o sistema de Seguridade Social nunca foi implementado em sua plenitude, não sendo respeitados nem seu orçamento, nem sua a concepção (BRAVO, 2004). 
O Serviço Social se introduz na saúde a partir de 1948, quando a Organização Mundial de Saúde - OMS muda o conceito de saúde até então adotado. Esse "novo" conceito passa a considerar o aspecto biopsicosocial, o que pressupõe a requisição de outros profissionais para o setor (BRAVO, 2004). A autora Maria Inês Souza Bravo, que possui diversas publicações na temática do Serviço Social e Saúde, aponta em seus estudos diversos fatores que consolidam a essa área como um importante campo de atuação profissional, entre eles: considera que a saúde possui um potencial revolucionário e de consenso, ressalta que a área é um campo privilegiado da luta de classes em que se chocam as concepções de vida das diferentes classes sociais e também por ter um valor amplamente compartilhado, entretanto, "a forma de distribuição desse direito consensual é que é o motivo do dissenso" (BRAVO,1996).

Sendo o Serviço Social uma profissão consolidada na saúde, conforme a resolução 287/98 do Conselho Nacional de Saúde - CNS e o trabalho na área já se consolida como campo de atuação para a categoria, nos propomos nesse trabalho a tratar da formação que esses profissionais vêm recebendo.

Os observadores da Reforma Sanitária, o Controle Social por meio das Conferências de Saúde constatam que a formação de recursos humanos para a área da saúde é um dos mais graves problemas para o sistema (LEAL, 2005). A formação para o trabalho na saúde do Brasil representa um ponto crítico, não só no Serviço Social, mas também nos demais cursos que atuam nesse campo. Nas Instituições de ensino superior são poucas ou inexistentes as matérias que tratem tal assunto:

"Nos currículos tradicionais, quando não há total ausência de conteúdos sobre o Sistema Único de Saúde, o que é menos freqüente nos cursos clássicos, como medicina, enfermagem e odontologia, mas comum nos cursos como a psicologia, o serviço social, a biologia, a educação 
física e a medicina veterinária, esse conhecimento termina apresentado como um dado isolado e não uma produção. A ênfase nos procedimentos supera amplamente o pensar saúde, constatando-se que os gestores e os formadores em saúde não têm gerado suficiente contato e aprendizado dos acadêmicos da área com o SUS e nem assegurado ao conhecimento em Saúde Coletiva a necessária familiaridade para que se componha com o núcleo de práticas de cada profissão. Trata-se de um paradoxo, na qual a realidade de saúde e os recursos fundamentais de atuação no SUS permanecem desconhecidos dos estudantes.” (BILIBIO \& CECCIN, 2004).

Falar da criação, gestão, organização e trabalho para o SUS é um ponto muito importante para a formação profissional, já que grande parte dos profissionais da saúde será empregada no sistema. Mesmo assim, a formação profissional que desde muito tempo esteve desvinculada dos debates que a sociedade fazia sobre a saúde da população e de novo modelo de saúde mais voltado aos interesses coletivos, persistiu e continuou formando profissionais voltados ao mercado de trabalho privado (LEAL, 2005).

Apesar de haver algumas propostas de transformações surgidas no interior do movimento sanitário para o setor saúde - como as diretrizes de criação do Sistema Único de Saúde que confluíram na VIII Conferência Nacional de Saúde e foram consolidadas na Constituição Federal de 1988 - a formação superior não conseguiu acompanhar essas mudanças propostas. Ocorreram algumas alterações nas grades curriculares, porém elas foram insuficientes não transformando, assim, o modo de produção desses profissionais. Portanto, podemos constatar que apesar de as experiências de mudanças curriculares advindas das novas Diretrizes Curriculares Nacionais para os Cursos da Saúde ${ }^{1}$, essas não representaram relevantes mudanças pedagógicas e metodológicas, mudanças na lógica de

\footnotetext{
1 "As universidades brasileiras foram convocadas a desenvolverem processos de mudanças nas graduações de saúde. Essas mudanças devem ser orientadas, de acordo com Noronha (2002), pela reorganização das praticas de saúde, onde a compreensão do trabalho no SUS deve acompanhar o transitar pelas diferentes lógicas assistenciais.” (LEAL, 2005)
} 
formação profissional, no sentido do desenvolvimento de habilidades e competências para que os trabalhadores desenvolvessem capacidade criativa para lidarem com a realidade do SUS (LEAL, 2005).

Como alternativa, variadas iniciativas têm surgido como tentativa de transformação das práticas profissionais, sobretudo, as atividades de extensão universitária:

“A Extensão Universitária busca aproximar os conhecimentos acadêmicos da realidade social, para que o choque desses saberes traga transformações tanto no estudante quanto reflexos na comunidade onde o programa está sendo desenvolvido. (...) Essa modalidade de atividade foi fruto de um esforço para que a ampliação da formação que a academia oferecia para a sociedade. Em especial no caso da saúde, a extensão possibilita aos estudantes uma abordagem epstemológica e social mediante a exposição precoce e oportuna da realidade.” (SANTANA, 1999)

Entretanto, a extensão universitária vem se consolidando como uma forma de inserção dos estudantes na comunidade, com práticas essencialmente assistenciais e não como uma alternativa de modificar o compromisso social da universidade com a formação de profissionais que respondam às necessidades do Estado Brasileiro.

Outra alternativa, que possui o intuito de promover mudanças na formação de futuros profissionais de diferentes áreas de atuação e aproximar esse profissionais às diversas realidades existentes e aos seus futuros campos de atuação são os estágios de vivência.

Os estágios de vivência são estratégias que já vem sendo utilizadas por outros setores na tentativa de aproximar os estudantes a realidade e desafios da atuação profissional. Segundo a Federação dos Estudantes de Agronomia do Brasil - FEAB, (que organiza até hoje o seu estágio interdisciplinar de vivência na realidade agrária) os estágios de vivência foram criados no intuito de estimular a construção da consciência crítica dos 
estudantes e provocá-los quanto às ações da universidade, a formação recebida e a estrutura da sociedade. Ao longo da vivência o estudante é colocado em contato com a realidade brasileira e com os instrumentos de transformação desta, bem como com a sua organização e mobilização.

Partindo dessas experiências, o movimento estudantil da área de saúde percebeu a lacuna existente entre ensino e o serviço decorrente do pouco contato que esses profissionais possuíam com o SUS, sua realidade e seus desafios, criando, posteriormente, os estágios de vivência no SUS (LEAL, 2005).

A primeira proposta de âmbito nacional foi o Estágio Nacional Interdisciplinar de Vivência no SUS - (ENIV-SUS), que devido a dificuldades de articulação entre as executivas e federações de representação nacional dos estudantes e o Ministério da Saúde não foi realizado. Como desdobramento dessa articulação foram desenvolvidas outras duas iniciativas importantes: Projeto Escola de Verão e Vivências e Estágios na Realidade de Sistema Único de Saúde do Rio Grande do Sul - VER-SUS/RS (TORRES, 2005).

Em 2001, a Diretoria Nacional dos Estudantes de Medicina (DENEM) procurou a Escola de Saúde Pública do Rio Grande do Sul (ESP/RS) para apoiar a realização do V Estágio Nacional e I Estágio Regional de Vivência no Sistema Único de Saúde. A ESP/RS apoiou a iniciativa e criou o projeto Escola de Verão que abriu o campo de vivência na gestão de sistemas e serviços de saúde no Rio Grande do Sul (BILIBIO \& CECCIN, 2004). Segundo Bilibio e Ceccin (2004) o projeto VER-SUS/RS foi uma ampliação do projeto Escola de Verão, os estudantes organizados no Núcleo de Trabalhos em Saúde Coletiva (NETESC) e a ESP/RS pretendiam ampliar a oferta desse projeto aos diversos estudantes dos diferentes cursos da saúde. Esse estágio-vivência teve, além de um foco na gestão, um aprofundamento do conhecimento acerca do controle social, intersetorialidade, e 
a implantação do Programa Saúde da Família no estado. Dentro do espaço das discussões no VER-SUS/RS foi levantada a proposta de se ampliar a participação estudantil para debater em conjunto a formação dos profissionais de saúde.

Em setembro de 2002, aconteceu em Porto Alegre o I Congresso Gaúcho de Estudantes Universitários em Saúde que tentou partir de uma abordagem multiprofissional a formulação de proposições para o fortalecimento da formação e ação dos estudantes dentro do contexto do SUS. Essa foi a primeira vez que os estudantes universitários da saúde se reuniram em um grupo multiprofissional e multiinstitucional para discutir encaminhamentos destinados as mais diferentes instâncias da saúde. Houve a participação dos $16^{2}$ cursos de ensino superior com formação voltada para a área da saúde.

Após essas iniciativas, que tiveram repercussão nacional, os estudantes organizados na Comissão de Representação do Movimento Estudantil da Área de Saúde em parceria com o Ministério da Saúde pretendiam inserir os estudantes dos 16 cursos da saúde e de todo país, em todos os setores do SUS. Essa era uma estratégia para aproximar os estudantes universitários do setor aos desafios inerentes ao sistema de saúde no país.

O Projeto Vivências e Estágios na Realidade de Sistema Único de Saúde do Brasil VER-SUS/Brasil surgiu como um complemento a formação acadêmica que os estudantes possuíam até então. Uma alternativa que nasce no interior do movimento estudantil, e, que após um longo debate com o gestor federal do SUS, ganha amplitude nacional. Essa estratégia elaborada pela Comissão de Representação do Movimento Estudantil da Área da Saúde em parceria com o Ministério da Saúde é, antes de mais nada, uma proposta de capacitação de recursos humanos para o SUS, pois possibilita a futuros profissionais verem

\footnotetext{
${ }^{2}$ São considerados como cursos da área da saúde os 14 cursos previstos na Resolução de $n^{\circ} 287 / 98$ do Conselho Nacional de Saúde, acrescidos de Administração de Sistemas e Serviços de Saúde e Administração Hospitalar.
} 
a realidade, senti-la, experimentando-a, dialogando e refletindo sobre ela em seu possível meio de trabalho (Leal, 2005).

As vivências e estágios ocorreram num período entre 10 a 15 dias com grupos interdisciplinares, compostos basicamente de uma capacitação sobre o sistema, reconhecimento do local a ser vivenciado, vivência, estágio e a avaliação final.

Cabe ainda ressaltar que no VER-SUS/Brasil os estudantes não intervém na realidade em que estão inseridos, mas sim, observam, discutem e conhecem melhor o sistema.

Os estudantes interessados em participar do estágio deveriam se inscrever na página do projeto na Internet. A seleção dos inscritos foi pactuada na coordenação nacional do VER-SUS/Brasil e cada executiva foi responsável pela seleção dos estudantes de seu curso.

Assim, essa pesquisa propôs-se a analisar estratégia VER-SUS/Brasil na formação de estudantes universitários de Serviço Social através da identificação de suas expectativas, bem como suas impressões posteriores sobre o referido estágio de vivência, contribuindo, assim, para uma maior compreensão da formação dos assistentes sociais no que concerne à política de saúde e suscitando reflexões sobre a formação profissional como um todo. Partindo da hipótese de que os estágios, tanto no que se refere ao seu cenário de realização quanto as vivências que proporcionam, são um importante complemento para a formação em saúde de assistentes sociais, aplicamos questionários em 67\% dos estudantes de Serviço Social da cidade de Brasília que participaram do VER-SUS/Brasil em 2004 e analisaremos os conteúdos das respostas.

No Capítulo 01 “Abordagem Teórico Metodológica” descrevemos o processo metodológico. O capítulo seguinte “ Apresentação e Análise do objeto de Estudo: O VERSUS/Brasil na perspectiva dos Estudantes” foi dividido em dois momentos: inicialmente 
tratamos dos dados e analisamos os cursos de saúde em geral; o perfil dos estudantes que participaram do estágio e como esses estudantes avaliaram a vivência, em seguida analisamos as impressões do estudantes de Serviço Social a respeito do VER-SUS/Brasil para consolidar os objetivos deste estudo. 


\section{ABORDAGEM TEÓRICO-METODOLÓGICA}

Esta é uma pesquisa empírica que busca analisar os efeitos da estratégia VERSUS/Brasil sob a ótica dos estudantes de Serviço Social. Trata-se de um estudo qualitativo, com abordagem descritiva e exploratória que possui além das informações e dados preliminares obtidos por meio de revisão bibliográfica e documental, pesquisa de campo com a aplicação de questionários estruturados aos estudantes de Serviço Social de Brasília que participaram da vivência em 2004. Constitui-se como uma pesquisa social, baseada na linha de pensamento da sociologia compreensiva (MINAYO, 1992).

Os dados foram estudados segundo a análise de conteúdo proposta por Minayo (1992), genericamente, essa análise é usada para designar o tratamento de dados, assim, “visa ultrapassar o nível do senso comum e do subjetivismo na interpretação e alcançar uma vigilância crítica frente à comunicação de documentos, textos literários, biografias, entrevistas ou observação”.

A busca das informações referentes ao conhecimento do processo de formação acadêmica de profissionais na área da saúde, das reais necessidades do SUS em relação à qualificação de recursos humanos, da relação entre o processo de formação acadêmica no setor saúde, a atuação profissional no SUS e a compreensão da proposição metodológica dos estágios de vivência no SUS, se deu tanto através da reflexão gerada fruto dos questionários respondidos pelos colaboradores, quanto com o estudo bibliográfico.

Na tentativa de traçar um panorama mais geral sobre as impressões da estratégia VER-SUS nos estudantes e uma avaliação geral sobre o estágio foram utilizados os dados tabulados pelo Ministério da Saúde na “Avaliação do Projeto VER-SUS/Brasil Questionário para estudantes”. Este foi o questionário aplicado pelo Ministério durante a 
vivência em 2004 com o objetivo de avaliar o estágio e responder a três questões norteadoras:

(a) Em que medida o Projeto VER-SUS/Brasil respondeu aos objetivos pactuados com a Coordenação Nacional?

(b) Como se deu a construção e implementação do Projeto-Piloto do VER-SUS Brasil?

(c) Quais foram os resultados do Projeto-Piloto do VER-SUS Brasil para os estudantes participantes?

Esse instrumental de avaliação foi composto de 07 (sete) páginas que compreendiam uma breve apresentação, orientações para o preenchimento do questionário, termo de consentimento informado para participação na avaliação e o questionário com 35 questões em que o estudante deveria marcar a opção que concordava.

Dadas as proporções do questionário, a pesquisadora selecionou as questões que mais corroboravam com os objetivos do presente estudo.

Foram selecionadas as questões que tratavam de quantitativos de distribuição dos estagiários por estado, curso e tipo de instituição. Em seguida, foram analisadas as questões que tratavam da formação que os estudantes haviam adquirido: onde ocorreu a aproximação com o SUS, se já haviam realizado outros estágios de vivência ou projetos de extensão universitária, se realizaram estágio profissional em saúde pública e se a inserção no projeto incentivou a participação em movimentos sociais diversos. Finalizamos com a análise das questões referentes ao impacto da vivência nos estudantes, entretanto, só foram selecionadas as que tinham maior afinidade com os objetivos da pesquisa, ou seja, que tratavam da compreensão dos estudantes acerca da noção de saúde, Reforma Sanitária, gestão do SUS, Atenção à Saúde, Educação na Saúde e o Controle Social. 
Embora o questionário do Ministério da Saúde ofereça um panorama geral da participação dos estudantes no VER-SUS, é importante observar como os estudantes de Serviço Social avaliam a sua participação no referido estágio de vivência para que possamos refletir melhor acerca da formação dos assistentes sociais em saúde e para que possamos pensar estratégias diferenciadas para dinamizar e incrementar essa formação. Nesse sentido, esse estudo se propõe a analisar as impressões dos estudantes de Serviço Social que participaram do VER-SUS, e assim, contribuir para a formação de futuros assistentes sociais, fomentando o debate acerta do Serviço Social e a Saúde.

Foram convidados a participar da pesquisa 03 (três) estudantes de Serviço Social da Universidade de Brasília que participaram do projeto em 2004. Apesar de não haver um banco de dados do Ministério da Saúde que constasse quais os estudantes que haviam participado da vivência a pesquisadora possuía o contato desses estudantes em um arquivo pessoal, tendo em vista que participou do processo de seleção dos estagiários que realizariam a vivência no núcleo regional centro-oeste representando a Executiva Nacional do Estudantes de Serviço Social - ENESSO.

Esta amostra representa 100\% dos estudantes do Serviço Social de Brasília que participaram da vivência como estagiários.

Foi elaborado um instrumental com 06 (seis) questões abertas. As perguntas do instrumental foram elaboradas no intuito de testar a hipótese de pesquisa, ou seja, na tentativa de captar a compreensão e as impressões que os estudantes de Serviço Social tiveram acerca da vivência. Foi pedido que aos estudantes evitassem deixar perguntas sem respostas para que a analise dos dados não fosse prejudicada.

As questões sugeriram que os estudantes partissem de uma visão mais geral sobre o que seriam os estágios de vivência no SUS, até sobre o que seria, na sua compreensão, o 
VER-SUS/Brasil para a sua formação profissional. A análise do conteúdo partiu da tentativa de captar a concepção que os estudantes possuíam sobre os estágios de vivência no SUS (questão 01) para assim ter como referência inicial essa percepção.

Na questão seguinte buscou-se inferir qual a importância dos estágios de vivência para a formação do futuro profissional do Serviço Social, considerando a sua descrição anterior sobre a sua concepção sobre os estágios de vivência. Em seguida o entrevistado deveria evidenciar e explicitar o que considerava mais importante no VER-SUS/Brasil para que o pesquisador pudesse testar a sua hipótese de pesquisa.

Na terceira pergunta pediu-se que o estudante comparasse as experiências de formação em saúde que possuía e assim testar se o estudante conseguiu compreender o estágio vivência como uma nova metodologia de ensino que possibilita aos estudantes questionarem a sua própria formação profissional.

Na tentativa de confirmar a questão anterior a pergunta 04 pediu aos estudantes que citassem o que diferenciava o VER-SUS/Brasil e os outros cenários de sua formação. Buscando evidenciar qual a relação existente entre a prática profissional passada na vida acadêmica e o que se vivenciou no estágio. Também pediu-se que o estudante citasse se havia essa relação ou se o que se aprende na academia estava desconexo da realidade vivenciada.

A última questão foi livre para que o estudante, caso se sentisse à vontade, comentasse qualquer ponto, que por algum motivo não foi aprofundado, e, assim, pudesse ser retomado ou que levantasse outros pontos de vista até então não explicitados.

Os questionários foram enviados aos colaboradores via correio eletrônico (e-mail). A opção metodológica escolhida para o estudo se justifica pela dificuldade de realização de entrevistas com os estudantes, já que alguns deles não residem mais na cidade de Brasília. 
É importante ressaltar que essa metodologia não prejudicou o desenvolvimento da pesquisa, uma vez que, por se tratar de um estudo exploratório, ele não pretende esgotar as reflexões sobre as questões de pesquisas propostas.

Inicialmente foi feito um contato prévio via correio eletrônico (em anexo) para saber se os estudantes aceitariam participar do estudo.

Em seguida, foi enviada a apresentação da proposta de pesquisa aos sujeitos para que os objetivos do projeto pudessem ser expostos aos participantes. Junto à Carta de Apresentação foi enviado o Termo de Consentimento Livre e Esclarecido e o instrumental de pesquisa (em anexo).

Como todo o contato com os estudantes foi feito via e-mail não pudemos recolher os Termos de Consentimento assinados, assim o estudante ao retornar o instrumental respondido afirmava que haviam compreenderam as informações contidas na apresentação e no termo, caracterizando, assim, a adesão a pesquisa. O questionário foi respondido e retornado ao pesquisador via correio eletrônico (e-mail).

Após a etapa de aplicação do instrumental, foi feita a análise de conteúdo dos dados e informações recebidas dos colaboradores. Procurando, assim, através da inferência no tratamento de dados propiciar uma interpretação mais profunda do conteúdo.

Dos 03 (três) questionários enviados aos sujeitos da pesquisa 02 (dois) foram devolvidos à pesquisadora para análise. Os questionários respondidos foram nomeados e numerados seguindo a ordem de recebimento, $\mathrm{P}$ de participante e a seqüência de recebimento, P1 e P2. As falas dos sujeitos da pesquisa serão utilizadas enquanto base argumentativa do estudo e serão referenciadas conforme classificação descrita.

Este estudo foi proposto enquanto trabalho de conclusão do curso de graduação de Serviço Social e buscou colaborar para a produção de conhecimentos acerca do processo de 
formação dos estudantes de Serviço Social inseridos no campo da saúde, não sendo esse estudo um trabalho conclusivo sendo que novas respostas às questões propostas podem surgir de novos estudos sobre o assunto. 


\section{Apresentação e Análise do Objeto de Estudo: O VER-SUS/Brasil na perspectiva dos}

$\underline{\text { estudantes }}$

A fase de apresentação dos dados se dará em dois momentos: na primeira etapa trataremos das análises obtidas através dos dados de avaliação da vivência em 2004, fornecidos pelo Ministério da Saúde com o objetivo de mostrar o perfil dos estudantes que participaram da vivência em 2004 e qual foi a avaliação feita por esses estudantes. Na segunda etapa analisaremos como os estudantes do Serviço Social avaliaram VERSUS/Brasil utilizando o instrumental aplicado pela pesquisadora.

\subsection{O VER-SUS/Brasil segundo a “Avaliação do Projeto VER-SUS/Brasil -} Questionário para estudantes”

A I edição do VER-SUS/Brasil foi realizada no período entre agosto e setembro de 2004, em 19 (dezenove) estados brasileiros das cinco regiões geográficas (norte, nordeste, sul, sudeste, e centro-oeste) e contou com a participação de 1067 (mil e sessenta e sete) estudantes das 16 profissões da área da saúde. Entretanto, desse total 477 (quatrocentos e setenta e sete) estudantes que responderam ao questionário de avaliação, ou seja, 44,7 \% dos estagiários participaram do processo de avaliação (ver tabelas 01 e 02). Como se tratava de uma pesquisa que seguia as recomendações de Ética em Pesquisa do Conselho Nacional de Saúde a participação dos estagiários no estudo foi facultativa.

Estagiários que responderam a pesquisa

\begin{tabular}{|l|c|c|}
\hline & Freqüência & Porcentagem \% \\
\hline Respondentes & $\mathbf{4 7 7}$ & $\mathbf{4 4 , 7}$ \\
\hline Em Branco & 590 & 55,3 \\
\hline Total & 1067 & 100 \\
\hline $\begin{array}{l}\text { Tabela 01 - "Avaliação do Projeto VER-SUS/Brasil - } \\
\text { Questionário para estudantes" - Tabulação feita pelo Ministério } \\
\text { da Saúde }\end{array}$ \\
\hline
\end{tabular}


Distribuição dos estagiários respondentes da avaliação nos estados em que ocorreram a Vivência

\begin{tabular}{|l|c|c|}
\hline Estado & Freqüência & $\begin{array}{c}\text { Porcentagem } \\
\%\end{array}$ \\
\hline PA & 43 & 9 \\
\hline AM & 10 & 2,1 \\
\hline TO & 0 & 0 \\
\hline BA & 22 & 4,6 \\
\hline PB & 27 & 5,7 \\
\hline MA & 24 & 5 \\
\hline PI & 30 & 6,3 \\
\hline CE & 0 & 0 \\
\hline PE & 0 & 0 \\
\hline SE & 0 & 0 \\
\hline GO & 16 & 3,4 \\
\hline MS & 0 & 0 \\
\hline PR & 29 & 6,1 \\
\hline SC & 10 & 2,1 \\
\hline RS & 89 & 18,6 \\
\hline MG & 53 & 11,1 \\
\hline ES & 22 & 4,6 \\
\hline SP & 75 & 15,7 \\
\hline RJ & 27 & 5,7 \\
\hline Total & 477 & 100 \\
\hline Tabela 02 - "Avaliação do Projeto VER-SUS/Brasil - \\
Ministério da Saúde & & \\
\hline & & \\
\hline
\end{tabular}

Os estudantes de Serviço Social representaram 6,08\% (29) dos estudantes que responderam a avaliação, sendo 22 (75\%) de instituições públicas e 06 (25\%) de 
instituições particulares. Contrariamente ao que observamos no estudo ${ }^{3}$ do Ministério da Educação - MEC, em que as Instituições de Ensino Superior possuem um número de vagas 5 (cinco) vezes superior as vagas no ensino público constatamos que há uma maior adesão ao projeto dos estudantes provenientes das Instituições de Ensino Públicas, sobretudo no curso de Serviço Social que possui 13.788 (81,1\%) vagas existentes nos 116 (72\%) cursos de instituições privadas e 3.065 (18,2\%) vagas nas 46 (28\%) instituições públicas (ver tabelas 03, 04 e 05).

Tipos de Instituição dos estudantes de Serviço Social que participaram do VER-SUS/Brasil

\begin{tabular}{|l|c|c|}
\hline Tipo de Instituição & Freqüência & $\begin{array}{c}\text { Porcentagem } \\
\text { (\%) }\end{array}$ \\
\hline Pública & 22 & 75 \\
\hline Privada & 06 & 20 \\
\hline Outros & 01 & 05 \\
\hline Total & 29 & 10 \\
\hline $\begin{array}{l}\text { Tabela 03 - "Avaliação do Projeto VER-SUS/Brasil - Questionário } \\
\text { para estudantes" - Tabulação feita pelo Ministério da Saúde }\end{array}$ \\
\hline
\end{tabular}

Tipos de Instituição de Ensino Superior (IES) que possuem cursos de Serviço Social

\begin{tabular}{|c|c|c|}
\hline $\begin{array}{l}\text { Tipo de IES que possui o } \\
\text { curso de Serviço Social }\end{array}$ & Freqüência & $\begin{array}{c}\text { Porcentagem } \\
\text { (\%) }\end{array}$ \\
\hline Privada & 116 & 72 \\
\hline Pública & 46 & 28 \\
\hline Total & 162 & 100 \\
\hline
\end{tabular}

Com esses dados podemos observar que o movimento estudantil é mais ativo dentro das instituições públicas de ensino superior e que apesar dessas instituições possuírem as

${ }^{3}$ A Trajetória dos Cursos de Graduação na Saúde: 1991 - 2004. 
mesmas deficiências na formação profissional que as instituições públicas, pois, são diretrizes nacionais para os cursos da saúde, os estudantes do ensino privado parecem perpetuar a lógica do mercado não questionando a formação que recebem.

Vagas para o curso de Serviço Social por tipo de Instituição de ensino Superior

\begin{tabular}{|c|c|c|}
\hline $\begin{array}{l}\text { Número de Vagas do curso de } \\
\text { Serviço Social por tipo de IES }\end{array}$ & Frequência & $\begin{array}{c}\text { Porcentagem } \\
\text { (\%) }\end{array}$ \\
\hline Privada & 13.788 & 81,8 \\
\hline Pública & 3.065 & 18,2 \\
\hline Total & 16.853 & 100 \\
\hline
\end{tabular}

Um fato que reafirma a importância de iniciativas que aproximem os estudantes a realidade do SUS e dos seus desafios de construção implementação, como os estágios de vivência, além dos diversos estudos publicados, é o fato que a maioria dos estudantes respondentes, 357 (74,8\%) afirmou que a sua aproximação com o SUS se deu majoritariamente em espaços extra-curriculares (ver tabela 06).

\begin{tabular}{|l|c|c|}
\hline $\begin{array}{l}\text { Em qual espaço se deu a maior parte de sua aproximação ao } \\
\text { SUS? }\end{array}$ & Frequencia & $\begin{array}{c}\text { Porcentagem } \\
\text { (\%) }\end{array}$ \\
\hline Curricular & 108 & 22,6 \\
\hline Extra-Curricular & 12 & $\mathbf{7 4 , 9}$ \\
\hline Não Responderam & 477 & 100 \\
\hline Total & \multicolumn{2}{|c|}{} \\
\hline $\begin{array}{l}\text { Tabela 06 - "Avaliação do Projeto VER-SUS/Brasil - Questionário para estudantes" - Tabulação feita pelo Ministério da } \\
\text { Saúde }\end{array}$
\end{tabular}

O que confirma a defasagem na formação dos profissionais de saúde tornando, assim, o estágio em um importante espaço de reflexão e debate sobre a formação 
profissional uma vez que a aproximação com a realidade e desafios do SUS se deu em espaços majoritariamente que não pertenciam as grades curriculares desses estudantes.

O VER-SUS/Brasil foi um projeto construído no interior do Movimento Estudantil fundamentado com diversos debates e discussões acerca da formação profissional, o papel do estudante na sociedade e como o estudante poderia transformar a realidade a qual está inserido.

Podemos verificar também nessa avaliação a grande adesão que os estudantes dos cursos em geral tiveram sobre o VER-SUS/Brasil já que 452 (94,8\%) dos estudantes se sentiram motivados em participar da consolidação do projeto (ver tabela 07).

\begin{tabular}{|l|c|c|}
\hline $\begin{array}{l}\text { A participação na Vivencia estimulou sua inserção na } \\
\text { consolidação do VER-SUS/Brasil? }\end{array}$ & $\begin{array}{c}\text { Freqüência } \\
\text { Sim }\end{array}$ & $\begin{array}{c}\text { Porcentagem } \\
\text { (\%) }\end{array}$ \\
\hline Não & 142 & $\mathbf{9 4 , 8}$ \\
\hline Não Responderam & 477 & 2,9 \\
\hline Total & 11 & 2,3 \\
\hline $\begin{array}{l}\text { Tabela 07 - "Avaliação do Projeto VER-SUS/Brasil - Questionário para estudantes" - Tabulação feita pelo Ministério da } \\
\text { Saúde }\end{array}$ \\
\hline
\end{tabular}

No que diz respeito à vivência em si a avaliação feita pelo Ministério da Saúde reafirmou a relevância da estratégia enquanto um instrumento capaz de fazer com que o estudante consiga refletir a respeito da realidade em que está inserido, questionar a sua formação profissional, agregar e ampliar seu conhecimento a respeito do SUS e da sua criação, seus desafios e a sua gestão. Como observamos nas tabelas seguintes os estudantes concordaram que a vivência lhes proporcionou reflexão a acerca de diversos aspectos.

Na tabela 08, notar-se-á que 464 (97,27\%) dos respondentes concordam que vivência incitou a sua reflexão a respeito do papel do estudante enquanto agente de 
transformação social, e, na tabela 09, 452 (94,75\%) dos respondentes concordam que a vivência foi um estímulo para que refletissem a necessidade de mudanças da graduação. Apesar de a freqüência ter sido pouco menor, 401 (84,06\%) dos respondentes concordam que a vivência os estimulou a participar de movimentos de mudanças na graduação (tabela 10), esses movimentos são dos tipos mais variado.

\begin{tabular}{|l|c|c|}
\hline $\begin{array}{l}\text { A participação na vivência me estimulou a refletir sobre o } \\
\text { meu papel como agente de transformação social. }\end{array}$ & $\begin{array}{c}\text { Freqüência } \\
\text { Discordo }\end{array}$ & $\begin{array}{c}\text { Porcentagem } \\
\text { (\%) }\end{array}$ \\
\hline Nem discordo nem concordo & 07 & 1,05 \\
\hline Concordo & $\mathbf{4 6 4}$ & $\mathbf{9 7 , 2 7}$ \\
\hline Não Responderam & 01 & 0,22 \\
\hline Total & 477 & 100 \\
\hline $\begin{array}{l}\text { Tabela 08 - "Avaliação do Projeto VER-SUS/Brasil - Questionário para estudantes" - Tabulação feita pelo Ministério da } \\
\text { Saúde }\end{array}$
\end{tabular}

\begin{tabular}{|l|c|c|}
\hline $\begin{array}{l}\text { A participação na vivência me estimulou a refletir sobre os } \\
\text { processos de mudanças na graduação. }\end{array}$ & $\begin{array}{c}\text { Freqüência } \\
\text { Discordo }\end{array}$ & $\begin{array}{c}\text { Porcentagem } \\
\text { (\%) }\end{array}$ \\
\hline Nem discordo nem concordo & 17 & 04,84 \\
\hline Concordo & $\mathbf{4 5 2}$ & $\mathbf{9 4 , 7 5}$ \\
\hline Não Responderam & 04 & 0,84 \\
\hline Total & 477 & 100 \\
\hline $\begin{array}{l}\text { Tabela 09 - "Avaliação do Projeto VER-SUS/Brasil - Questionário para estudantes" - Tabulação feita pelo Ministério da } \\
\text { Saúde }\end{array}$ & \\
\hline
\end{tabular}




\begin{tabular}{|l|c|c|}
\hline $\begin{array}{l}\text { A participação na vivência me estimulou a participar em } \\
\text { movimentos em torno das mudanças na graduação. }\end{array}$ & $\begin{array}{c}\text { Freqüência } \\
\text { Discordo }\end{array}$ & $\begin{array}{c}\text { Porcentagem } \\
\text { (\%) }\end{array}$ \\
\hline Nem discordo nem concordo & 60 & 2,72 \\
\hline Concordo & $\mathbf{4 0 1}$ & $\mathbf{8 4 , 0 6}$ \\
\hline Não Responderam & 03 & 0,63 \\
\hline Total & 477 & 100 \\
\hline $\begin{array}{l}\text { Tabela 10 - "Avaliação do Projeto VER-SUS/Brasil - Questionário para estudantes" - Tabulação feita pelo Ministério da } \\
\text { Saúde }\end{array}$
\end{tabular}

Por haver pouco contato dos estudantes com o SUS, iniciativas como o VERSUS/Brasil tem se mostrado por meio de diversos estudos como uma estratégia que proporciona aos estudantes uma aproximação as diversas áreas de atuação no sistema, entre elas a gestão.

A maioria dos estudantes que participaram concordam que o estágio lhes proporcionou além dessa aproximação a realidade tão diversa quanto a reflexão a respeito dessa gestão do SUS (tabela 11), ou seja, 454 (95,17\%) e também 427 (89,52\%) dos estudantes também concordam que o conceito de gestão pode ser ampliado após a vivência (tabela 12).

\begin{tabular}{|l|c|c|}
\hline $\begin{array}{l}\text { A participação na vivência me trouxe grande motivação a } \\
\text { refletir a respeito dos processos de Gestão do Sistema Único } \\
\text { de Saúde. }\end{array}$ & $\begin{array}{c}\text { Freqüência } \\
\text { Discordo }\end{array}$ & $\begin{array}{c}\text { Porcentagem } \\
\text { (\%) }\end{array}$ \\
\hline Nem discordo nem concordo & 18 & 0,22 \\
\hline Concordo & $\mathbf{4 5 4}$ & $\mathbf{9 5 , 1 7}$ \\
\hline Não Responderam & 04 & 0,84 \\
\hline Total & 477 & 100 \\
\hline $\begin{array}{l}\text { Tabela 11 - “Avaliação do Projeto VER-SUS/Brasil - Questionário para estudantes" - Tabulação feita pelo Ministério da } \\
\text { Saúde }\end{array}$ & \\
\hline
\end{tabular}


O estágio possibilitou vivenciar, debater e por fim ampliar os diversos conceitos que são do cotidiano do trabalho na saúde mas que são pouco vistos durante a graduação.

\begin{tabular}{|l|c|c|}
\hline $\begin{array}{l}\text { A participação na vivência ampliou de maneira significativa } \\
\text { minha compreensão a respeito da Gestão do Sistema Único } \\
\text { de Saúde. }\end{array}$ & $\begin{array}{c}\text { Freqüência } \\
\text { Discordo }\end{array}$ & $\begin{array}{c}\text { Porcentagem } \\
\text { (\%) }\end{array}$ \\
\hline Nem discordo nem concordo & 37 & 1,88 \\
\hline Concordo & $\mathbf{4 2 7}$ & $\mathbf{8 9 , 5 2}$ \\
\hline Não Responderam & 04 & 0,84 \\
\hline Total & 477 & 100 \\
\hline $\begin{array}{l}\text { Tabela 12 - "Avaliação do Projeto VER-SUS/Brasil - Questionário para estudantes" - Tabulação feita pelo Ministério da } \\
\text { Saúde }\end{array}$ & \\
\hline
\end{tabular}

A Atenção a Saúde compreende uma outra categoria importante na formação profissional dos estudantes já que visa o atendimento às demandas pessoais e das exigências ambientais, compreendendo três grandes campos: a assistência, as intervenções ambientais e as políticas externas no setor saúde (Ministério da Saúde, 2004). A vivência motivou grande parte dos estudantes, 460 (96,44\%), a refletirem a respeito da Atenção a Saúde (tabela 13).

\begin{tabular}{|l|c|c|}
\hline $\begin{array}{l}\text { A participação na vivência me trouxe grande motivação a } \\
\text { refletir de forma mais aprofundada a respeito da Atenção a } \\
\text { Saúde. }\end{array}$ & $\begin{array}{c}\text { Freqüência } \\
\text { Porcentagem } \\
\text { Discordo }\end{array}$ \\
\hline Nem discordo nem concordo & 11 & 0,42 \\
\hline Concordo & $\mathbf{4 6 0}$ & $\mathbf{9 6 , 4 4}$ \\
\hline Não Responderam & 04 & 0,84 \\
\hline Total & 477 & 100 \\
\hline $\begin{array}{l}\text { Tabela 13 - "Avaliação do Projeto VER-SUS/Brasil - Questionário para estudantes" - Tabulação feita pelo Ministério da } \\
\text { Saúde }\end{array}$ & \\
\hline
\end{tabular}


Na tabela 14, podemos ver que segundo a maioria dos estagiários, 444 (93\%), a vivência também proporcionou que eles ampliassem a compreensão sobre a Atenção a Saúde.

\begin{tabular}{|l|c|c|}
\hline $\begin{array}{l}\text { A participação na vivência ampliou de maneira significativa } \\
\text { minha compreensão a respeito da Atenção a Saúde. }\end{array}$ & $\begin{array}{c}\text { Freqüência } \\
\text { Porcentagem } \\
\text { (\%) }\end{array}$ \\
\hline Nem discordo nem concordo & 03 & 0,7 \\
\hline Concordo & 444 & 5 \\
\hline Não Responderam & 06 & $\mathbf{9 3}$ \\
\hline Total & 477 & 100 \\
\hline $\begin{array}{l}\text { Tabela 14 - "Avaliação do Projeto VER-SUS/Brasil - Questionário para estudantes" - Tabulação feita pelo Ministério da } \\
\text { Saúde }\end{array}$ & \multicolumn{2}{|l}{} \\
\hline
\end{tabular}

Outro aspecto significativo da vivência para grande parte dos estudantes, 371 (77,7\%), foi a possibilidade que o estágio lhes proporcionou para que eles compreendessem o que foi o processo da reforma sanitária brasileiro (tabela 15).

\begin{tabular}{|l|c|c|}
\hline $\begin{array}{l}\text { A participação na vivência me estimulou a compreender } \\
\text { melhor o processo de reforma sanitária brasileira. }\end{array}$ & $\begin{array}{c}\text { Freqüência } \\
\text { Porcentagem } \\
\text { (\%) }\end{array}$ \\
\hline Nem discordo nem concordo & 73 & 6,3 \\
\hline Concordo & 371 & $\mathbf{7 7 , 7}$ \\
\hline Não Responderam & 03 & 0,7 \\
\hline Total & 477 & 100 \\
\hline $\begin{array}{l}\text { Tabela 15 - "Avaliação do Projeto VER-SUS/Brasil - Questionário para estudantes" - Tabulação feita pelo Ministério da } \\
\text { Saúde }\end{array}$
\end{tabular}

O Controle Social tem um papel fundamental no SUS, pois é nessa instância que se efetiva a participação popular, a fiscalização, e o controle sobre as ações em cada nível de governo, entretanto, essa é uma área pouco vista durante a formação profissional. Mas, 
como afirmam 87,63\% (418) dos estudantes a participação no VER-SUS/Brasil lhes ampliou a compreensão a respeito do Controle Social no SUS (tabela 16).

\begin{tabular}{|l|c|c|}
\hline $\begin{array}{l}\text { A participação na vivência ampliou de maneira significativa } \\
\text { minha compreensão a respeito do Controle Social no } \\
\text { Sistema Único de Saúde. }\end{array}$ & 11 & Preqüência \\
\hline Discordo & 43 & 2,3 \\
\hline Nem discordo nem concordo & $\mathbf{4 1 8}$ & $\mathbf{8 7 , 6 3}$ \\
\hline Concordo & 05 & 1,04 \\
\hline Não Responderam & 477 & 100 \\
\hline Total & \multicolumn{2}{|c|}{} \\
\hline $\begin{array}{l}\text { Tabela 16 - "Avaliação do Projeto VER-SUS/Brasil - Questionário para estudantes" - Tabulação feita pelo Ministério da } \\
\text { Saúde }\end{array}$ & \\
\hline
\end{tabular}

Além do Controle Social a noção de saúde que os estudantes possuíam pode ser alterada, possibilitando que fosse considerada a saúde como um todo e não a ausência de doenças. Podemos confirmar isso na tabela 17, em que 95,85\% (457) dos respondentes afirmam que a vivência ampliou a noção de saúde que possuíam.

\begin{tabular}{|l|c|c|}
\hline $\begin{array}{l}\text { A participação na vivência contribuiu de forma significativa } \\
\text { para que eu ampliasse a minha noção de saúde. }\end{array}$ & $\begin{array}{c}\text { Freqüência } \\
\text { Discordo }\end{array}$ & $\begin{array}{c}\text { Porcentagem } \\
\text { (\%) }\end{array}$ \\
\hline Nem discordo nem concordo & 12 & 1,25 \\
\hline Concordo & $\mathbf{4 5 7}$ & $\mathbf{9 5 , 8 5}$ \\
\hline Não Responderam & 02 & 0,4 \\
\hline Total & 477 & 100 \\
\hline $\begin{array}{l}\text { Tabela 17 - “Avaliação do Projeto VER-SUS/Brasil - Questionário para estudantes" - Tabulação feita pelo Ministério da } \\
\text { Saúde }\end{array}$
\end{tabular}

Os estudantes também afirmaram que o conceito de Educação em Saúde foi ampliado com a vivência, assim 420 (88,05\%) estudantes concordaram (tabela 18). 


\begin{tabular}{|l|c|c|}
\hline $\begin{array}{l}\text { A participação na vivência ampliou de maneira significativa } \\
\text { minha compreensão a respeito da Educação em Saúde. }\end{array}$ & Freqüência & $\begin{array}{c}\text { Porcentagem } \\
\mathbf{( \% )}\end{array}$ \\
\hline Discordo & 14 & 2,93 \\
\hline Nem discordo nem concordo & 37 & 7,72 \\
\hline Concordo & $\mathbf{4 2 0}$ & $\mathbf{8 8 , 0 5}$ \\
\hline Não Responderam & 06 & 1,3 \\
\hline Total & 477 & 100 \\
\hline $\begin{array}{l}\text { Tabela 18 - "Avaliação do Projeto VER-SUS/Brasil - Questionário para estudantes" - Tabulação feita pelo Ministério da } \\
\text { Saúde }\end{array}$
\end{tabular}

Para finalizar o último item do questionário da avaliação considerado pela pesquisadora foi a Integralidade. Este se trata de um princípio constitucional do SUS, que garante ao cidadão ser atendido na sua totalidade, partindo da prevenção de doenças até o mais difícil tratamento de uma patologia, não excluindo nenhuma doença (Ministério da Saúde, 2004). Assim, 442 (92,68\%) estagiários concordam que a vivência possibilitou a compreensão a respeito da Integralidade no SUS (tabela 19).

\begin{tabular}{|l|c|c|}
\hline $\begin{array}{l}\text { A participação na vivência ampliou de maneira significativa } \\
\text { minha compreensão a respeito da Integralidade no Sistema } \\
\text { Único de Saúde. }\end{array}$ & Freqüência & $\begin{array}{c}\text { Porcentagem } \\
\mathbf{( \% )}\end{array}$ \\
\hline Discordo & 07 & 1,46 \\
\hline Nem discordo nem concordo & 23 & 4,82 \\
\hline Concordo & $\mathbf{4 4 2}$ & $\mathbf{9 2 , 6 8}$ \\
\hline Não Responderam & 05 & 1,04 \\
\hline Total & 477 & 100 \\
\hline $\begin{array}{l}\text { Tabela 19 - “Avaliação do Projeto VER-SUS/Brasil - Questionário para estudantes" - Tabulação feita pelo Ministério da } \\
\text { Saúde }\end{array}$ & \multicolumn{2}{|l}{} \\
\hline
\end{tabular}


Esse contato proporcionado pelos estágios de vivência possibilita aos estudantes imergirem em uma realidade prática, uma roda viva de aprendizagem, em que o estudante ao mesmo tempo apreende e vivencia a realidade na qual está inserido, troca experiências com os outros estagiários, com os gestores que acolheram o estágio em seus municípios e com os profissionais do sistema, diferente de seus estágios curriculares já que não atuam em sua área específica de formação não estando assim restritos a sua pratica profissional específica.

A avaliação dos estudantes fornecida pelo Ministério da Saúde reafirmou que o VER-SUS/Brasil contribui sobremaneira na formação dos estudantes uma vez que permite a esses estudantes conhecer, vivenciar, discutir e debater conceitos e locais de atuação pouco vistos durante a graduação.

Esse tipo de experiência é muito positiva uma, pois, possibilita a todos os segmentos envolvidos repensar a saúde, as práticas e a formação profissional, ampliando esses conceitos e aproximando das reais necessidades do sistema e da população.

\subsection{A Avaliação do VER-SUS/Brasil segundo os estudantes de Serviço Social}

Na pesquisa realizada com os estudantes de Serviço Social os entrevistados relataram que compreendem esse tipo de experiência como “ocasiões em que se pode questionar, observar e aprender na prática, o desenvolvimento do SUS em alguma localidade do país, vivenciando sua realidade e contribuindo para seu aperfeiçoamento e melhor articulação entre os envolvidos” (P1) “de forma interdisciplinar e partindo de suas próprias vivências” (P2). Ou seja, possibilitam um contato com a realidade em que os estudantes podem relacionar a teoria e a prática. Conforme observamos anteriormente as 
vivências são oportunidades em que os estudantes podem imergir numa realidade distante da vista na academia, podendo questionar, discutir, debater e construir, de forma interdisciplinar, os conceitos acerca da saúde.

"O contato com a realidade, a prática, são extremamente enriquecedores, pois além de permitir que se participe ativamente de uma área importante para a profissão, a troca de experiências com os profissionais de Serviço Social, e os de outras áreas, contribui para que as noções de participação, compromisso, trabalho em equipe, interdisciplinariedade e a própria escolha profissional sejam alcançados e aprimorados. ” (P1)

Os entrevistados reconheceram a falta de contato que os estudantes, de uma forma geral possuem do SUS compreendendo que o projeto representa uma importante estratégia para a formação de recursos humanos para o sistema.

"Como sabemos, muitos estudantes universitários entram e saem da universidade sem conhecer o sistema de saúde pública brasileiro, principalmente no que tange a sua história e aos seus princípios. Por isso, compreendo que esse projeto é uma estratégia importantíssima para a formação de recursos humanos para SUS e consequentemente para a melhoria da qualidade desse sistema." (P2)

Também foi apontado que o estágio se mostra como uma alternativa que os estudantes têm de com conhecer, observar, vivenciar e questionar a realidade do SUS de forma interdisciplinar, através da prática cotidiana diferentemente da que é vista nos estágios curriculares, pois, atém de inserir os estudantes em localidades diferentes das suas, no estágio de vivência os estudantes não intervêm nessa realidade a qual estão inseridos.

"através dos estágios de vivência podemos relacionar de forma mais aprofundada a teoria e a prática e também nos possibilita novos aprendizados, permitindo que a nossa compreensão da profissão e do local em que se realiza o estágio seja ampliada.

Destaco ainda a importância da troca de informações e conhecimentos entre os estudantes de diferentes cursos para a construção de uma relação de respeito entre os futuros profissionais." (P2)

"na vivência do SUS não se pode atuar como estagiário, é um trabalho de observação, discussão e pesquisa." (P1) 
Além dessa metodologia diferenciada adotada no VER-SUS/Brasil que proporcionou conhecer e vivenciar a realidade e desafios do SUS, esse método também tem o objetivo unir estudantes dos diversos cursos da saúde em prol de um objetivo comum: a consolidação e a efetivação do Sistema Único de Saúde do Brasil. Proporciona também que os estudantes vivenciem uma realidade pouco vista nos estágios curriculares, como a interdisciplinariedade, que acaba por tornar a vivência como um complemento a formação profissional deficiente.

"como a maioria dos estudantes realizaram o estágio em outro estado, conheceram diferentes realidades, o que permite refletir sobre a importância da relação entre os projetos de governo e a implementação do SUS. (...)

Considero, que ações desta natureza são de suma importância para a efetivação SUS nas próximas décadas, por aproximar os estudantes desta realidade e formar profissionais que lutem pela saúde pública de qualidade, ou seja, prioriza uma política de recursos humanos para o SUS. ” (P2)

"Ela (a vivencia) complementa o exercício da prática profissional do estágio curricular, no sentido de que reforça o olhar do estudante sobre a práxis, e ainda o leva a refletir sobre os pontos de vista de outros profissionais, o que muitas vezes não acontece nos campos de estágio. “(P1)

Mesmo sendo o Serviço Social uma profissão da saúde reconhecida pela resolução n²87/98 do CNS, um dos entrevistados ressaltou que essa ligação só foi possível, pois, já havia feito estágio na área da saúde e que o VER-SUS/Brasil lhe possibilitou aprofundar e relacionar a essa experiência acadêmica, pois tendo o Serviço Social um vasto campo de atuação (Judiciário, Assistência Social, Educação, entre outros) alguns estudantes podem se formar sem cursar matérias que tratem da Política de Saúde.

"Para mim foi possível relacionar esta experiência com a formação acadêmica, por já fazer estágio na área e cursar disciplinas relativas à temática, possibilitando ter uma visão mais ampla sobre a administração do SUS e conhecer a realidade do sistema em outra cidade. 
No entanto, sabemos que no Serviço Social podemos priorizar várias áreas de atuação e que boa parte dos estudantes nunca tiveram contato com a política de saúde, nunca cursaram uma disciplina sobre a saúde.” (P2)

Outro ponto levantado na entrevista foi o fato de que o estágio peca pela falta conteúdo teórico. Ou seja, que por mais que a vivência seja importante não se deve desconsiderar a base teórica a respeito do SUS, sua criação, gestão e desafios para as diferentes profissões.

"Acredito que o projeto falha na questão teórica, pois se concentra mais nas visitas as instituições e destina pouco tempo para as reflexões destas, ou seja, falta uma base teórica no estágio. Observo que esta necessidade não é só para o Serviço Social, outros estudantes que fizeram estágio comigo também sentiram falta dessa base.” (P2)

"O VER-SUS é uma experiência diferente do que normalmente temos em nossa formação acadêmica, por envolver diferentes cursos em um mesmo projeto e ter um processo de aprendizagem que prioriza as nossas vivências” (P2)

Os estágios de vivência proporcionaram aos estudantes “um contato com a realidade e a troca de experiência com outros profissionais assistentes sociais ou não" (S1) "para a construção de uma relação de respeito entre os futuros profissionais" (S2).

Os cenários onde foram realizadas as vivências permitiram a reflexão sobre as contradições existentes na implementação da política de saúde uma vez que se pode observar “ a importância da relação entre os projetos de governo e a implementação do SUS.” (S2). Também possibilitou que os estudantes que faziam estágio na saúde pudessem conhecer melhor os diversos níveis de atuação no SUS. Entretanto, algumas debilidades foram apontadas: como a falta do referencial teórico e mais debates sobre a pratica dos estudantes. 
Apesar das entrevistas apontarem algumas falhas no que tange ao aspecto teórico os estudantes, afirmam que o estágio é uma importante estratégia capaz de incitar as mudanças necessárias na graduação.

As entrevistas foram respondidas por inteiro, os entrevistados apontaram de uma forma geral que o VER-SUS/Brasil é uma importante experiência para a formação profissional que além de contribuir para que "as noções de participação, compromisso trabalho em equipe, interdisciplinariedade e a própria escolha profissional sejam alcançados e ampliados” (S1). Pudemos constatar que esses estudantes reconhecem a formação profissional deficiente que recebem com relação a política de saúde e assim a vivência se torna um complemento importante a quem vai atuar nessa área. 


\section{Considerações Finais}

É necessário iniciar o processo de transformação na formação dos profissionais da área da saúde. Os trabalhadores do SUS continuam recebendo a formação tradicional. Formação essa que ocorre de forma fragmentada, que compartimenta o saber, dissocia a teoria e a prática e ignora a necessidade de formar profissionais aptos a atuarem de acordo com as necessidades e princípios do sistema.

A diversificação dos cenários de aprendizagem proporcionam a mudança na forma de construção do conhecimento, pois, possibilitam a construção do saber de forma coletiva, a partir das relações multiprofissionais e contato com a realidade do sistema. Assim, os estágios de vivência desenvolvem um papel fundamental para essa formação profissional, visto que, instiga uma visão crítica do estudante sobre o sistema e sua própria formação.

Os resultados das duas pesquisas apresentadas neste estudo apontam que o VERSUS/Brasil se constitui como uma estratégia importante na formação dos futuros profissionais do Serviço Social, pois possibilitam de forma interdisciplinar que eles compreendam, no cotidiano da vivência, por meio de debates, discussões, questionamentos e visitas ao sistema no qual estão inseridos. Apesar de muitas vezes os estudantes não observarem na prática a efetivação dos conceitos nos serviços vivenciados esses conceitos podem ser conhecidos, aprofundados, discutidos e debatidos durante a vivência.

A avaliação elaborada pelo Ministério da Saúde reafirmou a lacuna existente entre a formação em saúde e o trabalho no SUS. Observamos que atual sistema de ensino que estes estudantes freqüentam falha na aproximação dos estudantes com o SUS já que, majoritariamente, isso se dá em espaços extra-curriculares, mostrando o distanciamento entre a formação acadêmica e o mercado de trabalho na saúde que é em grande parte o setor 
público. Também por meio dos dados do Ministério notamos que o estágio de maneira geral foi um grande estimulador para os estudantes refletir, compreender e ampliar conceitos como controle social, atenção à saúde, reforma sanitária, integralidade no SUS, gestão e noção de saúde.

Nas entrevistas realizadas com os estudantes de Serviço Social podemos constatar que consideram o VER-SUS/Brasil como uma estratégia importante que complementa a formação acadêmica no que tange a política de saúde, devido ao pouco contato que esses estudantes têm com o SUS durante a formação acadêmica tradicional e que mesmo realizando estágio na área possuem poucos conhecimentos sobre o sistema, seus desafios, sua realidade, sua gestão e os diversos níveis de atuação.

Outro ponto levantado pelos futuros Assistentes Sociais é que o cotidiano da vivência é um cenário muito enriquecedor que proporciona a troca de experiências, o debate e o contato com as diversas profissões da saúde.

Esse é o diferencial que o VER-SUS/Brasil proporciona, aos participantes, uma visão crítica do estudante sobre o sistema, questionadora da realidade e capaz de observar as contradições impostas pelo capitalismo. 


\section{REFERÊNCIAS BIBLIOGRÁFICAS}

BRASIL. Constituição de República Federativa do Brasil. Senado, Brasília/DF, 1988.

BRASIL, Ministério da Saúde e Comissão de Representação do Movimento Estudantil em Saúde. Projeto VER-SUS/Brasil: Vivência e Estágio na Realidade do Sistema Único de Saúde. Brasília / DF, setembro de 2003.

BRASIL, Ministério da Saúde. Política de educação e desenvolvimento para o SUS: caminhos para a educação permanente em saúde: pólos de educação permanente. Brasília / DF, 2004.

BRASIL, Ministério da Saúde. Glossário do Ministério da saúde: projeto de terminologia em saúde. Brasília / DF, 2004.

BRAVO, Maria Inês de Souza. SERVIÇO SOCIAL E REFORMA SANITÁRIA: Lutas Sociais e Práticas Profissionais. São Paulo: Cortez; Rio de Janeiro: UERJ, 1996.

BRAVO, Maria Inês de Souza e MATOS, Maurílio Castro de. Reforma Sanitária e projeto ético político do Serviço Social: elementos para o debate. In: SAÚDE E SAERVIÇO SOCIAL. São Paulo: Cortez; Rio de Janeiro: UERJ, 2004.

CECCIM, Ricardo Burg; $\quad$ BILIBIO, Luiz Fernando Silva. Articulação com o Segmento Estudantil da Área de Saúde: uma Estratégia de Inovação na Formação de Recursos 
Humanos para o SUS. In: VER-SUS/Brasil: Caderno de Textos, Ministério da Saúde, Brasília, 2004.

IAMAMOTO, Marilda Vilela. A Questão Social no Capitalismo. In: Temporalis - Revista da Associação Brasileira de Ensino e Pesquisa em Serviço Social. Ano 2, n. 3 (jan/jul. 2001), p. 9-32. Brasília: ABEPSS, Grafline, 2001.

IAMAMOTO, Marilda Vilela. Transformações Societárias, alterações no “mundo do trabalho” e Serviço Social. In: Revista Ser Social nº 6 (jan/jun. 2000), p.45-78.

LEAL, Mariana Bertol. DA REALIDADE AOS DESAFIO: efeitos da iniciativa VERSUS/Brasil na formação de trabalhadores para o SUS. Porto Alegre, 2005.

MINAYO, Maria Cecília de Souza. O desafio do Conhecimento: pesquisa qualitativa em Saúde. Rio de Janeiro - São Paulo, Hucitec, 1992.

NETTO, José Paulo. CINCO NOTAS A PROPOSITO DA “QUESTÃO SOCIAL”. In: Temporalis - Revista da Associação Brasileira de Ensino e Pesquisa em Serviço Social. Ano 2, n. 3 (jan/jul. 2001), p. 41-49. Brasília: ABEPSS, Grafline, 2001.

OLIVEIRA, Richarla Fortunato de; MESQUITA, Sonia Tebet; SILVA, Cleonice da. A Formação Profissional, Interdisciplinariedade e seu Processo de Aquisição. In: Serviço Social e Saúde. Ano IV - N 4. São Paulo: UNICAMP, 2005. 
PEREIRA, Potyara Amazoneida Pereira. A questão social e as transformações das políticas saciais: respostas de Estado e da sociedade civil. In: Revista Ser Social $\mathbf{n}^{\circ} 6$ (jan/jun. 2000), p.119 - 132.

SANTANA, José Paranaguá; CASTRO, Janete Lima de (org.). Capacitação em Desenvolvimento de Recursos Humanos de Saúde CADRHS. EDUFRS. Natal, 1999.

SERRA, Rose Mary Souza. A questão social hoje. In: Revista Ser Social ${ }^{\circ} 6$ (jan/jun. 2000), p. 169-184.

STEIN, Rosa Helena. A (nova) questão social e as estratégias para seu enfrentamento. In: Revista Ser Social nº 6 (jan/jun. 2000), p.133 - 167

TORRES, Odete Messa. OS ESTÁGIOS DE VIVÊNCIA NO SISTEMA ÚNICO DE SAÚDE: DAS EXPERIÊNCIAS REGIONAIS À (TRANS)FORMAÇÃO POLÍTICOPEDAGÓGICA DO VER-SUS/BRASIL. Salvador, 2005.

TRIVELINO, Alexandra; LOPES, Aine; Oliveira, Nilzélia. As Novas Configurações da Sociedade Civil e dos Movimentos Sociais: alternativas e propostas de mudanças. In Revista Expressões Sociais. Ano 1 (1ºmestre de 2002), p. 51-58. 
05. ANEXOS 
Cara (nome do estrevistado),

Sou Thallyta Tomimatsu, formanda em Serviço Social e estou fazendo uma monografia sobre a impressão dos estudantes de serviço social sobre o Ver-sus, de forma que estou enviando por e-mail um questionário para aqueles que participaram dos estágios em vivência e aceitam participar da pesquisa.

A sua participação é muito importante para que a monografia seja realizada com

sucesso.

Agradeço a atenção e aguardo resposta.

Thallyta Tomimatsu 
(Nome do Entrevistado),

Você está sendo convidada a participar de uma pesquisa para o trabalho de conclusão de curso de Thallyta de Carvalho Tomimatsu, formanda em Serviço Social pela Universidade de Brasília - UnB .

Este estudo está sendo orientado pela Professora Denise Bomtempo Birche de carvalho e tem cunho estritamente acadêmico.

A sua participação consiste em responder o questionário e retorná-lo a mim, via email, dentro de 5 dias (até 4 de fevereiro de 2007).

Segue em Anexo:

A carta de Apresentação, Termo de Consentimento e o Instrumental da pesquisa.

Obrigada,

Thallyta Tomimatsu 


\section{CARTA DE APRESENTAČ̃̃O}

Você está sendo convidado a responder algumas perguntas sobre o VER-SUS/Brasil (Vivências e Estágios na Realidade do Sistema Único de Saúde). Suas respostas visam qualificar a busca de dados e informações que possam auxiliar na compreensão acerca da influencia do projeto VER-SUS no processo de formação dos estudantes de Serviço Social bem como as suas impressões posteriores ao estágio.

O conjunto das respostas servirá de base de análise para a pesquisa "O VERSUS/Brasil sob a perspectiva dos estudantes de Serviço Social”, proposta enquanto trabalho de conclusão de curso da estudante Thallyta de Carvalho Tomimatsu, formanda de Serviço Social da Universidade de Brasília - UnB. A pesquisa é orientada pela professora Denise Bomtempo Birche de Carvalho.

Sua participação consiste ler e compreender o Termo de Consentimento Livre e Esclarecido e se concordar responder as perguntas do questionário em anexo.

Ao responder as questões que compõem a pesquisa você estará participando de uma pesquisa de cunho acadêmico, que tem como objetivo compreender a influencia da estratégia VER-SUS no processo de formação dos estudantes de Serviço Social.

\section{TERMO DE CONSENTIMENTO LIVRE E ESLARECIDO DO PARTICIPANTE}

Conforme os esclarecimentos prestados na Carta de Apresentação, eu (nome do entrevistado) concordo em participar

voluntariamente deste estudo, sabendo ao responder o questionário estarei automaticamente afirmando que compreendi o que foi proposto e assim estarei participando do estudo. Sei também que será preservada a minha identificação assim como a de todas as pessoas referidas por mim. E minha participação na pesquisa não incorrerá em riscos ou prejuízos de qualquer natureza.

Fui esclarecido de que por ser uma participação voluntária e sem interesse financeiro não terei direito a nenhuma forma de remuneração ou gratificação.

Sei que poderei retirar o meu consentimento a qualquer momento, antes ou durante a realização do mesmo, inclusive sem nenhum motivo, bastando para isso informar a minha decisão de desistência, da maneira mais conveniente.

Eu, e somente eu, posso solicitar esclarecimentos durante todas as fases da pesquisa inclusive após a publicação das mesmas. 


\section{Questionário}

\section{Questões de entrevista:}

1) O que você compreende por estágios de vivência no SUS?

2) Você considera que os estágios de vivência influenciam a formação profissional?

Porquê e o quê você destacaria como mais importante?

3) Segundo a sua experiência, quais as principais afinidades e diferenças entre as experiências de estágios de vivência no SUS e outras práticas de formação acadêmica?

4) Qual a diferença do cenário onde se deu essa vivência dos outros cenários da formação?

5) Como esta experiência se relaciona com a prática profissional apreendida na formação acadêmica?

7) Você gostaria de complementar esta entrevista com algum dado ou sugestão que considera importante? 